\title{
An Observational Study of Venoplasty in Patients with Multiple Sclerosis
}

\author{
W. Pryse-Phillips, M. Stefanelli, K. Murphy-Peddle, B. Barrett
}

\begin{abstract}
Rationale: It is estimated that some hundreds of Canadian patients with multiple sclerosis (MS) have journeyed abroad to avail themselves of 'liberation therapy' (venoplasty) following the initial report by Zamboni et al in 2009. That study also led to public pressure upon Departments of Health in Canadian Provinces to fund the procedure. The present study was done in order to advise the Government of Newfoundland and Labrador as to whether or not it should do so. Methods: We conducted an observational study of 30 MS subjects who had submitted to venoplasty, using objective, semi-objective and subjective measures. Results: Significant subjective improvement was reported by half of the subjects at three months, although the degree of perceived improvement was less at 12 months. The objective and semi-objective tests employed did not indicate improvement in any area over the one-year follow-up period. Seven of the 29 subjects in whom CT venography was performed at the end of the study year were found to have uni- or bilateral occlusion or $>50 \%$ stenosis of at least one cervical draining vein, but they showed no deterioration in their clinical status compared to those in whom no venous occlusion nor stenosis was found. Conclusion: No objective improvement was found at one year in thirty MS subjects who had undergone venoplasty, although many reported a degree of subjective benefit.
\end{abstract}

RÉSUMÉ: Étude d'observation chez des patients atteints de sclérose en plaques qui ont subi une veinoplastie. Justification : On estime que des centaines de Canadiens atteints de sclérose en plaques (SP) se sont prévalu de la « thérapie de libération » (phlebographie) à l'étranger suite au compte rendu initial publié par Zamboni et al en 2009 et des pressions ont été exercées par le public pour que les Départements de santé des provinces canadiennes défrayent les coûts de cette intervention. Nous avons procédé à cette étude afin de conseiller le gouvernement de Terre-Neuve et du Labrador sur ce sujet. Méthode : Nous avons effectué une étude d'observation auprès de 30 patients atteints de SP qui ont subi une veinoplastie. Nous avons utilisé des mesures d'évaluation objectives, semi-objectives et subjectives. Résultats : Une amélioration subjective significative a été rapportée par la moitié des patients 3 mois après l'intervention, mais le degré d'amélioration perçue était moindre 12 mois après l'intervention. Les tests objectifs et semi-objectifs utilisés au cours de l'étude n'indiquaient pas qu'il y ait eu amélioration dans quelque domaine que ce soit au cours de la période de suivi d'un an. La phlebographie par tomodensitométrie effectuée chez 29 patients à la fin de l'année d'observation a montré une occlusion uni ou bilatérale ou une sténose de plus de 50\% d'au moins une veine cervicale de drainage chez 7 de ces patients, sans détérioration de l'état clinique comparé à l'état clinique de ceux chez qui aucune occlusion ou sténose veineuse n'a été mise en évidence. Conclusion : Aucune amélioration objective n'a été notée après un an d'observation chez 30 patients atteints de SP qui avaient subi une veinoplastie, malgré que plusieurs d'entre eux rapportaient un certain degré de bénéfice subjectif.

Can J Neurol Sci. 2013; 40: 203-209

The report of Zamboni et $\mathrm{al}^{1}$ suggesting that the manifestations of multiple sclerosis (MS) are the result of obstructions of the cerebral draining veins has led to intense professional and public scrutiny, concern, and in many cases, action. The so-called 'liberation therapy' for what those authors have named 'Chronic Cerebrospinal Venous Insufficiency' (CCSVI) was designed to correct such postulated obstructions but this procedure was not available in Canada when this study was envisaged. However, since 2009 many Canadian patients with MS have, at their own expense, journeyed to countries where it is available, in order to undergo it.

The reports on their return have varied, but the national public pressure on Provincial Governments to fund the procedure in Canada has led to Federal reviews that at first concluded that there were insufficient data to support the promotion of this form of treatment, although a Canadian Institutes for Health Research (CIHR)-sponsored expert working group has subsequently recommended a clinical trial. Before this recommendation was made, at the behest of the Government of Newfoundland and Labrador, we designed a study to observe the effects of the CCSVI 'liberation' procedure (venoplasty) on thirty MS patients from this province over one year.

\section{OBJeCTIVE}

To observe whether changes in mental or physical status occurred over 12 months in thirty patients with MS who chose to undergo 'liberation therapy' (venoplasty).

\section{MethodologY}

\section{Setting}

The MS Clinic at the Health Sciences Centre, St. John's, Newfoundland. Recruitment occurred between 01/Nov/2010

\footnotetext{
From the Department of Medicine, Division of Neurology, Multiple Sclerosis Clinic at the Health Sciences Centre, Memorial University of Newfoundland, St. John's, Newfoundland, Canada.

Received July 13, 2012. Final Revisions Submitted October 25, 2012 Correspondence to: William Pryse-Phillips, 7. Monkstown Road, St. John's, Newfoundland, A1C 3T1, Canada. Email: wpryse@mun.ca.
} 
and 01/Nov/2011. Data collection for each patient occurred over a 12-month follow-up period.

\section{Subjects}

All those patients in Newfoundland and Labrador with clinically-diagnosed multiple sclerosis (of any type) using the revised McDonald criteria ${ }^{2,3}$ who had expressed their intention of submitting to the 'liberation procedure' for CCSVI were eligible for the study.

Patients with MS (of any type) who were attending the Memorial University MS Clinic or other MS Clinics in the Province of Newfoundland and Labrador and who had expressed their intention of not submitting to the liberation procedure were also eligible for the study. All subjects were identified by the MS Clinic staff consecutively (and thus randomly). They were invited to enroll in the study after full disclosure of its nature, extent, risks and benefits. Those not intending to have venoplasty were recruited solely in order to blind the evaluating neurologist as to the treatment status of subjects in the study when assigning a Kurtzke Expanded Disability Status Scale $(\text { EDSS })^{4}$ score; they did not constitute a comparator group.

\section{Consent}

All subjects consented to undergo the additional testing required prior to and following their exposure to venoplasty or (in the case of the blinding volunteers) before and after an assigned date.

\section{Evaluation of Variables}

\section{A. Pre-procedure assessment}

The previous history and physical examination results of all patients eligible either as subjects or controls were on file in the MS Clinics. Their medical care during the study was provided by the treating neurologists who, after taking a history and performing a clinical examination, recorded their clinical findings and the number of clinical relapses experienced by the subjects.

Prior to the patients undergoing venoplasty, after clinical examination, the evaluating neurologist (WP-P) completed the EDSS. The same occurred in the cases of the control subjects before an assigned date. All subjects had been coached not to disclose whether or not they were planning to or had undergone venoplasty to the evaluating neurologist, who therefore remained blinded as to the treatment status of the forty subjects enrolled. In order to assess the patients' cognitive status for precise EDSS scoring, the revised Addenbrooke's Cognitive Evaluation (ACER) $)^{5}$ was administered.

The following tests were also used in order to measure patient outcomes in the 30 subjects who underwent venoplasty, but not in the control subjects.

Multiple Sclerosis Impact Scale (MSIS-29): This reliable, psychometrically- validated, patient-reported measure of the effects of MS on activities of daily living ${ }^{6}$ was completed independently by the subjects with their caregivers. A higher score denotes a worse outcome or situation.

Functional MS Composite (MSFC): This battery ${ }^{7}$, comprising three timed tests of neurologic function (namely a 25 -foot walk, the nine-hole peg test, and a 3-sec version of the PASAT (Paced Auditory Serial Addition Test) was administered by the MS Research Nurse-Coordinator who was already trained and certified for this function. Higher scores on the time to walk 25, and on the 9-hole peg test denote a worse outcome or situation; higher scores on the PASAT indicate a better outcome or situation.

Magnetic resonance imaging (MRI) examinations were performed within a month before subjects had undergone venoplasty. The MRI examinations were not performed on the blinding control subjects. The scans were done on a single machine at the Health Sciences Centre, St. John's, throughout the study and reported independently at another centre.

\section{B. Post-procedure assessments}

These occurred at 1, 3, 6 and 12 months (all within a twoweek time-window) after a specified date - either that on which the subject submitted to venoplasty or (in the case of control subjects) an assigned date arbitrarily chosen. The treating neurologists evaluated and managed the patients and blinding volunteers according to their clinical judgment. The evaluating neurologist examined the treated patients and control subjects in order to complete and score the EDSS, and administered the ACE-R, remaining blinded as to whether the subject had or had not undergone venoplasty. At each follow-up visit, the subjects with their caregivers completed the MSIS-29 and the MS Research Nurse scored the MSFC.

The MRI examinations were performed 3 and 12 months after the 30 subjects had undergone venoplasty.

Computed tomogram (CT) venograms were performed on all but one of the 30 subjects 12 months after they had undergone venoplasty, in order to determine the state of the venous drainage system of the brain after its performance.

\section{Statistical Methods}

To test the significance of any changes in scores between time points, a general linear model was used. Time was modelled as a within-subjects factor. The overall time trend was first assessed using an F-test and a sphericity assumption if Mauchly's test was non-significant. In cases where Mauchly's test of sphericity was significant, the Huynh-Feldt adjustment was applied to determine significance of change between time points. Significance for the F-test was declared at $<0.05$. If the F-test suggested some significant difference between scores across measurement times, a repeated contrast was used to assess significance between each pair of adjacent time points (e.g. Baseline vs. one month, one month vs. three months, etc.)

\section{RESULTS}

\section{Types of MS}

Ten venoplasty subjects had relapsing remitting MS, 17 had secondary progressive MS, and 3 subjects had primary progressive MS. (Table 1)

\section{Subjective Test Scores, Venoplasty Subjects}

On the MSIS-29, (Tables 2 and 4, Figure 1), there was an initial significant reduction in scores (indicating a better perception of the state of the person's health and well-being), but 
Table 1: Demographics

\begin{tabular}{l|l|l}
\hline & Treated subjects (30) & 'Control' subjects (10) \\
\hline M:F ratio & $8: 22$ & $2: 8$ \\
\hline No. Relapses in 12 months & $2 / 10$ & $0 / 6$ \\
\hline Withdrawals & 0 & $1 *$ \\
\hline Mean EDSS at entry & 5.2 & 4.3 \\
\hline
\end{tabular}

*One patient in the blinding control group withdrew after the 3rd month of the study due to the emergence of a malignancy.

Table 2: Scores at 5 time-points on the evaluation instruments used in the 30 venoplasty subjects

\begin{tabular}{|c|c|c|c|c|c|c|}
\hline Scale & Baseline Mean (SD) & 1 Month Mean (SD) & 3 Months Mean (SD) & 6 Months Mean (SD) & 12 Months Mean (SD) & P for time effect \\
\hline EDSS & $5.37(2.1)$ & $5.23(2.2)$ & $5.23(2.2)$ & $5.4(2.0)$ & $5.45(2.0)$ & 0.247 \\
\hline ACE-R & $82.87(12.9)$ & $85.43(12.5)$ & $86.6(10.8)$ & $87.17(10.4)$ & $86.67(10.6)$ & $<0.0005^{*}$ \\
\hline MSFC $-25 \mathrm{ft}$. walk time (sec) & $62.9(80.1)$ & $56.7(76.1)$ & $51.3(74.2)$ & $57.3(75.9)$ & $60.5(79.7)$ & 0.45 \\
\hline MSFC - 9 hole peg test (sec) & $62.5(74.2)$ & $58.1(83.3)$ & $58.3(84.3)$ & $60.5(84.2)$ & $67.0(88.5)$ & 0.13 \\
\hline MSFC - PASAT (\# of correct responses) & $31.3(19.2)$ & $32.5(20.9)$ & $31.9(21.1)$ & $34.6(19.9)$ & $30.2(22.0)$ & 0.39 \\
\hline MSIS & $77.47(26.1)$ & $56.93(17.6)$ & $58.1(23.7)$ & $62.6(23.4)$ & $66.37(24.2)$ & $<0.00059$ \\
\hline MSIS - physical subscale & $35.0(12.2)$ & $26.7(9.9)$ & $27.5(11.9)$ & $28.4(10.7)$ & $30.7(11.3)$ & \\
\hline \multirow[t]{2}{*}{ MSIS - psychosocial subscale } & $42.1(15.6)$ & $30.8(9.1)$ & $29.9(12.9)$ & $34.2(14.4)$ & $35.7(14.0)$ & \\
\hline & Median (25-75\%ile) & Median (25-75\%ile) & Median (25-75\%ile) & Median (25-75\%ile) & Median (25-75\%ile) & \\
\hline MSFC - $25 \mathrm{ft}$. walk time (sec) & $9.1(7-180)$ & $9.7(6.7-180)$ & $9.5(6.7-108)$ & $9.3(6.9-180)$ & $9.3(7.1-180)$ & \\
\hline MSFC - 9 hole peg test (sec) & $30.6(24.3-43.7)$ & $27.9(22.5-40.4)$ & $27.7(22.7-36.2)$ & $26.7(21.8-39.2)$ & $27.9(22.4-43.8)$ & \\
\hline MSFC - PASAT & $35.5(18.7-46.7)$ & $40.5(12.7-49.2)$ & $40.0(0-47.2)$ & $42.0(24.7-49.2)$ & $35.5(0-49)$ & \\
\hline
\end{tabular}

* All pairwise comparisons of the ACE-R scores between adjacent time points were non-significant other than baseline is significantly different from each other measure. I There was a significant drop in the MSIS scores from baseline to one month, but thereafter each pair of adjacent points were non-significantly different.

Table 3: Means of the EDSS and ACE-R scores assigned by the evaluating neurologist for the 10 blinding controls

\begin{tabular}{|c|c|c|c|c|c|}
\hline Scale & Baseline Mean (SD) & 1 Month Mean (SD) & 3 Months Mean (SD) & 6 Months Mean (SD) & 12 Months Mean (SD) \\
\hline ACE-R & $89.8(8.5)$ & $91.1(10.3)$ & $93.2(7.8)$ & $93.4(8.1)$ & $94.2(6.3)$ \\
\hline$\overline{\text { EDSS }}$ & $4.25(1.7)$ & $4.25(1.8)$ & $4.0(1.6)$ & $3.89(1.5)$ & $4.5(1.4)$ \\
\hline
\end{tabular}

Note: Blinding controls were recruited in order to blind the evaluating neurologist as to the treatment status of the patients evaluated, not to be comparable to cases. They should be regarded only as a separate group of people with MS.

thereafter patient-reported scores increased. The initial improvement was on average $26 \%$ below baseline, $(\mathrm{p}=0.001)$ but by one year the remaining improvement had declined to $15 \%$ below baseline $(p=0.01)$. When the scores in the groups with relapsing-remitting, secondary progressive or primary progressive MS were compared, no significant deviations were recordable. (Table 4)

\section{Patients' Final Assessment of the Value of the Procedure}

On an informal debriefing questionnaire, five patients claimed to be 'much' and eight claimed to be 'somewhat' better at 12 months. Specific improvements reported include warmer hands or feet, increased energy and better balance. Eleven said they improved initially but were now the same or worse. The remainder said that they were the same or worse as before the 


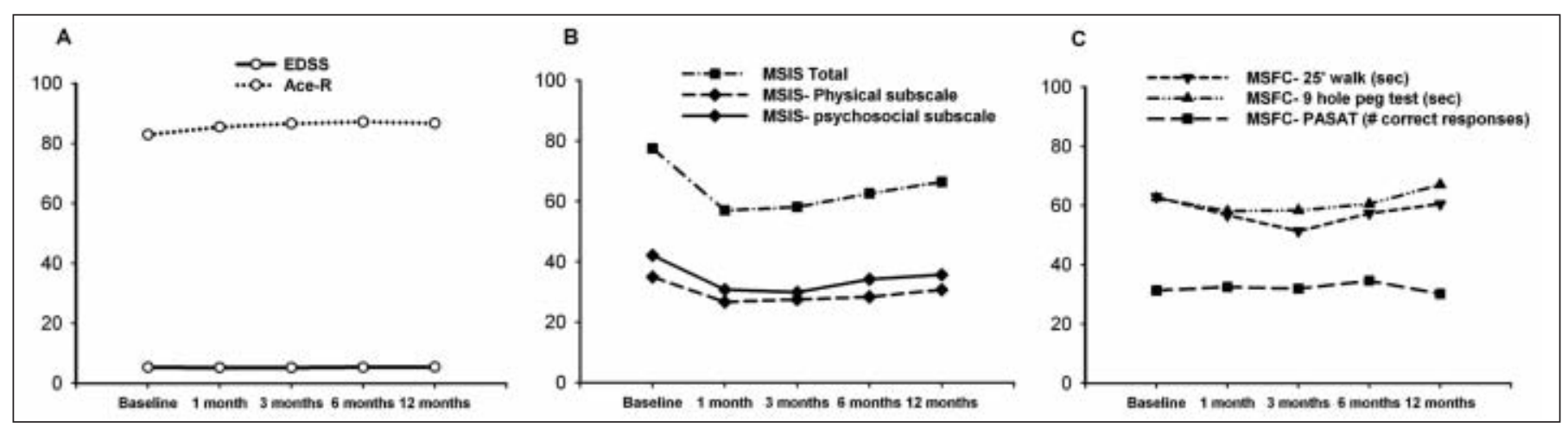

Figure 1: Mean EDSS, ACE, MSIS and MSFC scores over one year in 30 patients submitting to venoplasty. The reduction in scores in the MSIS (total) was highly significant at one month $(p=0.001)$ and significant at 12 months $(p=0.01)$, demonstrating a subjective perception of benefit. None of the other deviations on the EDSS or MSFC attained statistical significance.

procedure. Thus about half of the subjects said that they were the same or worse. Eighteen of 28 reported that they were disappointed in the results obtained from venoplasty.

When asked had their feelings about making the procedure available in Canada, 19 felt that everyone with MS should have it and eight said that MS patients should wait until the procedure is available in Canada or until research is complete.

\section{Objective Test Scores}

1. Scores on the MS Functional Composite (Tables 2, 4 and 5; Figure 1) showed no significant differences between the values for these three objective indices at baseline and at one year in patients who underwent venoplasty with or without demonstrated cervical vein occlusion at one year.

2. The EDSS scores assigned by the blinded evaluating neurologist (Tables 2, and 3, Figure 1) showed no significant differences at any time points during the study year on any values, either for controls or for venoplasty subjects with or without subsequently-demonstrated cervical venous occlusion.

3. CT Venography results at one year in 29 of the subjects who had undergone venoplasty showed that these were normal in 22 cases. In the remaining seven, internal jugular vein (IJV)

Table 4: Scores in the venoplasty subjects at 5 time-points. (Cases divided by MS subtype, Relapsing/Remitting (RR, $\mathrm{N}=10), 2^{\circ}$ Progressive (SP, $\left.\mathrm{N}=17\right)$ and $1^{\circ}$ Progressive (PP, $\mathrm{N}=3$ )

\begin{tabular}{|c|c|c|c|c|c|c|}
\hline Scale & $\begin{array}{l}\text { MS } \\
\text { Subtype }\end{array}$ & $\begin{array}{l}\text { Baseline } \\
\text { Mean (SD) }\end{array}$ & $\begin{array}{l}1 \text { Month } \\
\text { Mean (SD) }\end{array}$ & $\begin{array}{l}3 \text { Months } \\
\text { Mean (SD) }\end{array}$ & $\begin{array}{l}6 \text { Months } \\
\text { Mean (SD) }\end{array}$ & $\begin{array}{l}12 \text { Months } \\
\text { Mean (SD) }\end{array}$ \\
\hline \multirow[t]{3}{*}{ EDSS } & RR & $2.9(1.2)$ & $2.9(1.4)$ & $2.7(1.3)$ & $3.3(1.5)$ & $3.3(1.5)$ \\
\hline & SP & $6.4(1.1)$ & $6.2(1.4)$ & $6.3(1.2)$ & $6.2(1.4)$ & $6.3(1.3)$ \\
\hline & $\mathrm{PP}$ & $7.5(0.9)$ & $7.5(0.9)$ & $7.5(0.9)$ & $7.5(0.9)$ & $7.5(0.9)$ \\
\hline \multirow[t]{3}{*}{$\overline{\text { ACE-R }}$} & RR & $90(5.2)$ & $82.7(5.2)$ & $91.8(3.9)$ & $92.8(6.6)$ & $93.8(4.4)$ \\
\hline & SP & $77.3(14.3)$ & $79.5(12.9)$ & $82.7(12.7)$ & $82.7(11.1)$ & $81.6(11.2)$ \\
\hline & PP & $90.7(6.1)$ & $95.0(6.1)$ & $91.3(5.9)$ & $93.3(2.5)$ & $91.3(5.7)$ \\
\hline \multirow[t]{3}{*}{ MSFC - 25 ft. walk time $(\mathrm{sec})^{*}$} & RR & $6.3(4.6-8.1)$ & $6.0(4.6-7.2)$ & $6.0(4.6-6.9)$ & $5.8(4.9-7.4)$ & $6.5(4.6-8.2)$ \\
\hline & SP & $24.4(8.8-180)$ & $20.6(8.8-180)$ & $12.78 .2-143.8)$ & $18.7(8.6-113.3)$ & $10.0(8.0-180)$ \\
\hline & PP & 180 for all & 180 for all & 180 for all & 180 for all & 180 for all \\
\hline \multirow[t]{3}{*}{ MSFC -9 hole peg test (sec)* } & RR & $23.6(21.1-27.5)$ & $21.4(17.9-25.9)$ & $20.2(17.9-25.2)$ & $22.8(17.9-25.8)$ & $21.7(18.8-25.0)$ \\
\hline & SP & $35.7(28.3-51.3)$ & $31.1(27.2-51.5)$ & $32.6(25.9-39.2)$ & $30.9(26.3-57.9)$ & $33.6(27.3-75.7)$ \\
\hline & PPI & 300 & 300 & 300 & 300 & 300 \\
\hline \multirow[t]{3}{*}{$\overline{\mathrm{MSFC}-\mathrm{PASAT}^{*}}$} & RR & $39(33-50.2)$ & $45(32.2-51.0)$ & $42(24.7-47.5)$ & $44(23.2-52.0)$ & $44(0-53.5)$ \\
\hline & SP & $25(0-44.5)$ & $30(0-44)$ & $35(0-43.5)$ & $33(9-45)$ & $31(0-40.5)$ \\
\hline & PP & 45 & 54 & 48 & 51 & 48 \\
\hline \multirow[t]{3}{*}{ MSIS-29 } & RR & $55.6(21.0)$ & $40.0(11.3)$ & $37.8(11.9)$ & $49.9(22.3)$ & $50.5(21.3)$ \\
\hline & SP & $87.0(22.5)$ & $64.5(14.0)$ & $68.3(22.1)$ & $68.8(22.5)$ & $73.8(21.1)$ \\
\hline & PP & $96.3(12.9)$ & $70.7(11.5)$ & $67.7(22.1)$ & $69.7(20.1)$ & $77.0(31.0)$ \\
\hline
\end{tabular}

- Summarized as median and interquartile range (25th to 75th percentile); 9 Two of three scored 300 throughout; the third persons score ranged between 22 and 23.9 throughout. 
Table 5: Scores on the Evaluation Instruments Used in the Treated Subjects with vs. without Evidence of Venous Occlusion at 12 months

\begin{tabular}{l|l|l|l|l|l|l}
\hline Scale & $\begin{array}{l}\text { Vein } \\
\text { Status }\end{array}$ & $\begin{array}{l}\text { Baseline } \\
\text { Mean (SD) }\end{array}$ & $\begin{array}{l}\mathbf{1} \text { Month } \\
\text { Mean (SD) }\end{array}$ & $\begin{array}{l}\text { 3 Months } \\
\text { Mean (SD) }\end{array}$ & $\begin{array}{l}\text { 6 Months } \\
\text { Mean (SD) }\end{array}$ & $\begin{array}{l}\text { 12 Months } \\
\text { Mean (SD) }\end{array}$ \\
\hline EDSS & Normal & $5.8(1.6)$ & $5.6(1.8)$ & $5.6(1.9)$ & $5.7(1.7)$ & $5.8(1.7)$ \\
\hline & Abnormal & $4.1(3.0)$ & $4.1(3.0)$ & $3.9(2.8)$ & $4.2(2.8)$ & $4.3(2.8)$ \\
\hline ACER & Normal & $82.8(13.7)$ & $85.0(13.3)$ & $86.1(11.7)$ & $87.4(10.7)$ & $86.2(10.6)$ \\
\hline & Abnormal & $82.6(11.8)$ & $86.4(11.3)$ & $88.1(9.1)$ & $87.4(10.6)$ & $87.9(11.9)$ \\
\hline MSFC-25 ft. walk time (sec)* & Normal & $11.3(7.9-180$ & $12.9(7.6-180)$ & $99.6(7.4-180)$ & $9.3(7.2-180)$ & $9.6(7.6-180)$ \\
\hline & Abnormal & $7.9(4.5-180)$ & $8.4(4.7-42.9)$ & $6.9(4.7-24.6)$ & $7.8(4.9-46.7)$ & $7.3(4.6-180)$ \\
\hline MSFC-9 hole peg test (sec)* & Normal & $32.2(26-47.9)$ & $28.5(23.7-44.4)$ & $30.1(24.3-38.7)$ & $28.9(24-49.4)$ & $29.4(23.7-65)$ \\
\hline & Abnormal & $22.7(20.7-43.5)$ & $21(18-43.5)$ & $19.9(18.5-35.5)$ & $21.3(20.2-36.1)$ & $20.6(18.9-39.8)$ \\
\hline MSFC-PASAT* & Normal & $38.5(18.7-44)$ & $37.5(0-49.5)$ & $42(17.2-48.7)$ & $42.5(29.2-50.2)$ & $36.5(17.2-49.2)$ \\
\hline & Abnormal & $34(0-46)$ & $43(17-50)$ & $35(0-47)$ & $42(0-49)$ & $27(0-49)$ \\
\hline MSIS-29 & Normal & $79.9(25.6)$ & $57.1(15.3)$ & $56.8(19.1)$ & $59.0(17.0)$ & $64.0(20.8)$ \\
\hline & Abnormal & $69.0(29.9)$ & $59.1(24.8)$ & $62.3(37.5)$ & $69.4(37.0)$ & $70.1(34.3)$ \\
\hline
\end{tabular}

In retrospect, it appears that the seven subjects with venous occlusions at one year were slightly less impaired on the EDSS and MSFC, yet rated their own perception of health status as worse on the MSIS-29. The small numbers preclude estimations of significance.

occlusions (in one case bilaterally) or $>50 \%$ stenosis were seen.

The case group was further divided between the seven who had venous occlusion/stenosis shown by CT venography at 12 months after venoplasty and the 22 who had no such injury. These two groups of cases are compared in terms of the main assessment measures over time in Table 5. No significant differences between the EDSS, MSIS-29 or MSFC scores were seen at any time points between the two groups.

\section{MRI results}

All venoplasty patients underwent MRI examinations at baseline, 3 and 12 months except for two who lacked either a baseline or a 12-month scan respectively. Table 6 summarizes the MRI data. No significant alterations in the MRI indices (Gadolinium (Gd) Enhancing Lesion Count, T2 Lesion Volumes, T1 Lesion Volumes, New Larger T2 Lesion Count) were found.

\section{Discussion}

The theory that increased intracranial venous pressure plays a role in the genesis of MS may have face validity but treatments based upon this theory have not yet been subjected to blinded, randomized, controlled clinical trials. Despite this, there has been vociferous demand in Canada that the procedure should be made available as if it had proven worth, based upon anecdotal evidence of individual improvements in some of those who had submitted to the procedure in other countries. Provincial Departments of Health have thus been pressured by the opinion of an important segment of the public, reinforced by media comment, to fund venoplasty as a treatment for MS despite the lack of experimental trial evidence such as is required, for example, for pharmacological treatments.

In this real-world study of a consecutively-recruited series of 30 subjects with various forms of MS who underwent venoplasty, the evaluating neurologist remained blinded as to the treatment status of the subjects in all but one instance, when one venoplasty subject was involuntarily unblinded to him at six months.
Among the subjects who underwent the procedure, significant differences between their status at the start of the study and at its conclusion were not found on such objective tests as the timed tests in the MSFC and the MRI scan results, but were only found on a subjective measure, the MSIS-29. The scores on that questionnaire showed significant improvement at one and three months, with a gradual return towards the original scores at one year so that subjectively, the patients' mean rating of their improvement amounted to about $15 \%$. Although at the end of the study, in an informal question-and-answer session, some patients did report improvements in their perceived state such as warmer extremities, more energy, better balance and improvements in specific areas of their activities of daily living, such reports were seldom confirmed by clinical observation or objective testing.

These subjective scores contrast with the next two classes of observation. The semi-objective, highly systematized examination required for completion of the EDSS, performed here by a neurologist experienced in this assessment and blinded as to the status of the subjects he examined as regards venoplasty, yielded results indicating neither improvement nor worsening in their neurological status, whether or not they had undergone venoplasty and whether or not, after that procedure, CT venography had shown $>50 \%$ stenosis or actual thrombotic occlusion of their cervical veins.

The remaining methods of assessment employed were entirely objective. The MSFC timed tests of manual function, of ambulation and of cognitive function (targeting working memory) in the subjects who had undergone venoplasty all showed are that one year after the baseline assessments, there were neither significant improvements nor deterioration in their status. Magnetic resonance imaging scans done at baseline and repeated at 3 and at 12 months showed no significant changes in $\mathrm{T} 1$ or $\mathrm{T} 2$ lesion volume, no increase in gadolinium lesion counts and no change in the number of new larger T2 lesions at 3 or 12 months.

Before venoplasty was attempted, all subjects received Doppler ultrasound venography in their treating centre abroad. 
Table 6: MRI results in 30 venoplasty subjects before (baseline) and 3 and 12 months after venoplasty

\begin{tabular}{l|l|l}
\hline Variable & Mean (SD) & Median $\left(\mathbf{2 5}^{\text {th }} \mathbf{- 7 5 ^ { \text { th } }} \boldsymbol{\%}\right.$ ile) \\
\hline Gd Enhancing Lesion Count Baseline & $0.65(2.5)$ & 0 (0 to 0) \\
\hline New Gd Lesion Count 3 months & $0.58(1.8)$ & 0 (0 to 0) \\
\hline New Gd Lesion Count 12 months & $0.21(0.6)$ & 0 (0 to 0) \\
\hline T2 Lesion Volume Baseline & $17.2(20.6)$ & $13.5(1.8$ to 24.2) \\
\hline T2 Lesion Volume 3 Months & $17.5(20.5)$ & $13.7(1.9$ to 24.9) \\
\hline T2 Lesion Volume 12 Months & $17.9(20.5)$ & $14.0(2.2$ to 25.1) \\
\hline T1 Lesion Volume Baseline & $7.8(12.1)$ & $3.1(0.5$ to 9.6$)$ \\
\hline T1 Lesion Volume 3 Months & $7.9(12.1)$ & $3.9(0.6$ to 9.1$)$ \\
\hline T1 Lesion Volume 12 months & $8.0(11.8)$ & $4.8(0.6$ to 9.1$)$ \\
\hline New Larger T2 Lesion Count 3 Months & $1.4(4.1)$ & $0(0$ to 0$)$ \\
\hline New Larger T2 Lesion Count 12 months & $1.0(3.4)$ & $0(0$ to 0$)$ \\
\hline Siena PVBC 3 Months & $-0.21(0.58)$ & $-0.26(-0.64$ to 0.17$)$ \\
\hline
\end{tabular}

Note: The same GLM model approach was used to assess the significance of any change over measurements with regard to $\mathrm{T} 2$ lesion volume $(\mathrm{p}=0.41), \mathrm{T} 1$ lesion volume $(\mathrm{p}=0.46)$ and the number of $\mathrm{Gd}$ enhancing lesions seen $(\mathrm{p}=0.18)$

We think it safe to assume that, had any subject been shown to have had complete occlusion of a cervical vein at that time, venoplasty would not have been performed. Therefore, the subsequent demonstration of cervical venous occlusions in seven cases must be considered to represent new events, presumably related to the performance of the procedure.

The reason for the subjects' early perception of improvement is difficult to ascertain. Some reported that they had been given an intravenous injection that made them feel exactly the same as they had felt when, after previous relapses, they had received intravenous steroid therapy. However, information as to the nature of the substance injected, and the number of subjects so treated abroad, is not available to us. Also, almost all subjects were strongly advised to undertake a course of physiotherapy upon their return from foreign treatment centers and most did so.

These two confounders, coupled with a possible 'regression to the mean', might explain such highly significant subjective assessments of improved status in the first three months after the procedure, although not necessarily the (less significant) improvement rated at 12 months. While some might regard any

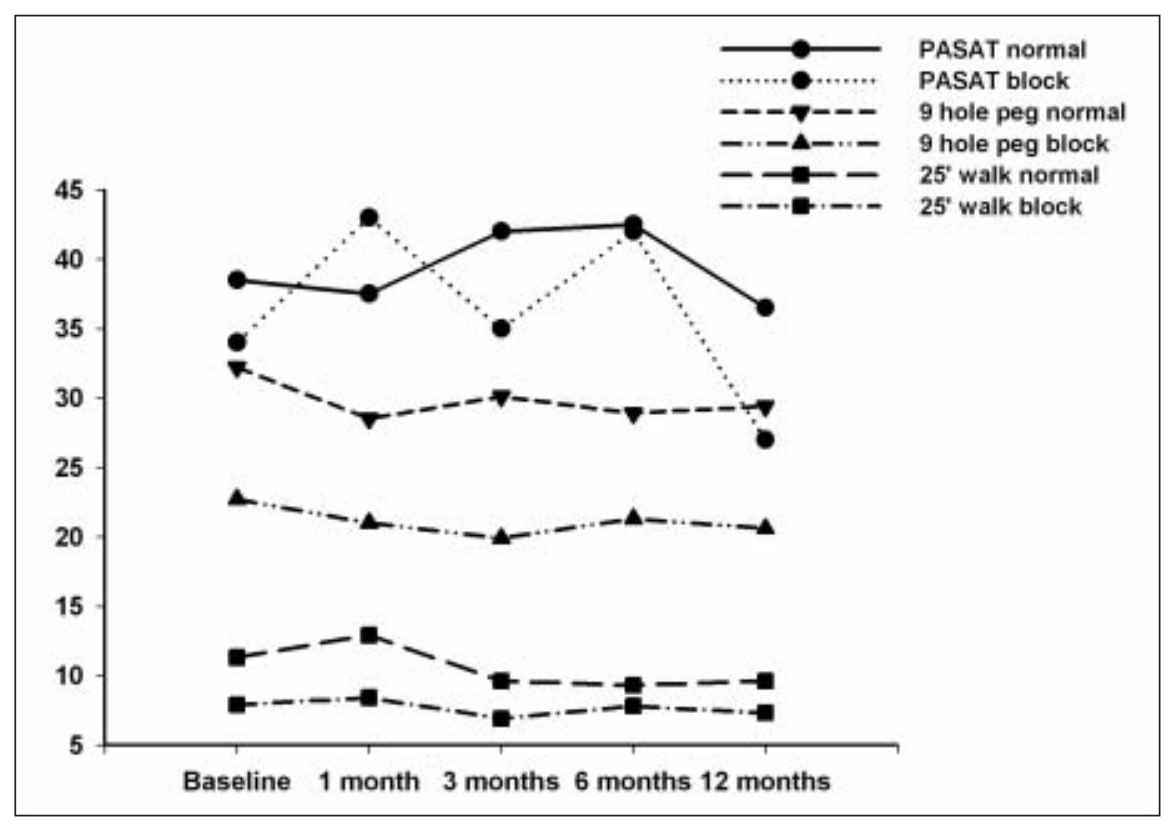

Figure 2: MSFC Scores in 22 Subjects without and seven with Evidence of Venous Blockage at one year. No statistically significant differences were seen at different time points on any of these 3 tests when comparing the groups with and without evidence of venous blockage at 12 months. 
such change as evidence of a "placebo effect", the nature and impact of such a phenomenon is not known to us, precluding further discussion.

The theory underlying the hypothesis that impaired venous drainage is a factor in the pathogenesis of multiple sclerosis has been strongly criticized, most recently by reviews from Italy 8.9 which cited the failure of other investigators to reproduce the results originally reported by Zamboni ${ }^{1}$, the lack of evidence from other sources that experimental or clinical occlusion of the cervical veins leads to clinical or pathological evidence of multiple sclerosis, the lack of evidence that iron deposition in the brain produces such effects, the variable methodologies used to document impairments in cerebral venous drainage (none supporting Zamboni's ${ }^{1}$ original results) and contradictory data concerning perfusion studies.

When this study was designed, expert opinion in Canada was that more evidence was required before venoplasty could approved; therefore a randomized controlled clinical trial (RCT) could not be mounted. An observational study appeared to be the next best option. Such a study design may be considered to be less authoritative than an RCT, even though the results are likely to be the same results. ${ }^{10-12}$ However, our work documents a 'real world' scenario which, in the context of Canada, reflects the fact that people with MS are still searching for a cure by submitting to this procedure abroad, on the basis of one highly publicized study from a single center, with anecdotal risks both of death and benefit, and with evidence of potential danger in the subsequent occlusion of the cervical veins, as occurred in about $25 \%$ of the subjects enrolled in our study.

Potential sources of bias or imprecision limiting the generalizability of our results include the fact that this was an observational study of only 30 patients, although it has been documented that results of this research design are usually congruent with those of randomized controlled trials..$^{10}$ Matching of the subjects and controls was not attempted because a realworld situation was being studied and because the only rationale for a 'control' group was to ensure that the evaluating neurologist was blinded as to the treatment status of the subject whom he was assessing in order to score the EDSS. The larger proportion of patients with secondary progressive MS in the treated group compared with the controls indicates a greater perception of the need for treatment among the more severely-affected patients. Finally, the procedures performed on the subjects studied here were done in different clinics in different countries, using methods that were unstandardized and that were not reported to us.

A cautious overall interpretation of results must be that in the subjects with MS studied here, no measurable, objective benefit was obtained as a result of venoplasty over the course of one year. The generalizability (external validity) of our study results is impossible to ascertain, but other clinical trials are likely to be mounted in Canada, if ethical approval is obtained.

\section{FUNDING}

The Government of Newfoundland and Labrador (Hon. Jerome Kennedy QC, Minister of Health) commissioned and financed the study without influencing the investigators as to its nature or scope and without imposing any requirements as to the publication of results.

\section{REFERENCES}

1. Zamboni P, Galeotti R, Menegatti E, et al. A prospective open-label study of endovascular treatment of chronic cerebrospinal venous insufficiency. J Vasc Surg. 2009;50:1348-58.

2. McDonald WI, Compston A, Edan G, et al. Recommended diagnostic criteria for multiple sclerosis; guidelines from the International Panel on the diagnosis of multiple sclerosis. Ann Neurol. 2001;50:121-7.

3. Polman CH, Reingold SC, Edan G, et al. Diagnostic Criteria for Multiple Sclerosis: 2005 Revisions to the "McDonald" Criteria. Ann Neurol. 2005;58:840-6.

4. Kurtzke JF. Rating neurological impairment in multiple sclerosis: an expanded disability scale (EDSS). Neurology 1983;33: 1444-52.

5. Mioshi E, Dawson K, Mitchell J, et al. The Addenbrooke's Cognitive Examination revised (ACE-R); a brief cognitive test battery for dementia screening. Int J Geriatr Psychiatry. 2006; 21(11):1078-85.

6. Hobart J, Lamping D, Fitzpatrick R , Riazi A, Thompson A. The Multiple Sclerosis Impact Scale. Brain 2001;124:962-73.

7. Polman $\mathrm{CH}$, Rudick RA. The Multiple Sclerosis Functional Composite. Neurology 2010;74 (Suppl 3):S8-15.

8. Baracchini C, Atzori M, Gallo P. CCSVI and MS: no meaning, no fact. Neurological Sciences. Online publication 9 May 2012 [Epub ahead of print].

9. Baracchini C, Perini P, Causin F, Calabrese M, Rinaldi F, Gallo P. Progressive multiple sclerosis is not associated with chronic cerebrospinal venous insufficiency. Neurology 2011;77:844-85.

10. Benson K, Hartz AJ. A comparison of observational studies and randomized controlled trials. N Engl J Med. 2000 Jun 22;342 (25): $1878-86$.

11. Concato J, Shah N, Horwitz RI. Randomized, Controlled Trials, Observational Studies and the Hierarchy of Research Designs. N Engl J Med. 2000 June 22; 342(25):1887-92.

12. Trojano M. Is it time to use observational data to estimate treatment effectiveness in multiple sclerosis? Neurology 2007;69:1478-9. 